\title{
Front Matter: Volume 9423
}

, "Front Matter: Volume 9423," Proc. SPIE 9423, Alternative Lithographic Technologies VII, 942301 (21 April 2015); doi: 10.1117/12.2192291 


\title{
PROCEEDINGS OF SPIE
}

\section{Alternative Lithographic Technologies VII}

\author{
Douglas J. Resnick \\ Christopher Bencher \\ Editors
}

23-26 February 2015

San Jose, California, United States

Sponsored by

SPIE

Cosponsored by

DNS Electronics, LLC

Published by

SPIE 
The papers included in this volume were part of the technical conference cited on the cover and title page. Papers were selected and subject to review by the editors and conference program committee. Some conference presentations may not be available for publication. The papers published in these proceedings reflect the work and thoughts of the authors and are published herein as submitted. The publisher is not responsible for the validity of the information or for any outcomes resulting from reliance thereon.

Please use the following format to cite material from this book:

Author(s), "Title of Paper," in Alternative Lithographic Technologies VII, edited by Douglas J. Resnick, Christopher Bencher, Proceedings of SPIE Vol. 9423 (SPIE, Bellingham, WA, 2015) Article CID Number.

ISSN: 0277-786X

ISBN: 9781628415254

Published by

SPIE

P.O. Box 10, Bellingham, Washington 98227-0010 USA

Telephone +1 3606763290 (Pacific Time) · Fax +1 3606471445

SPIE.org

Copyright (C) 2015, Society of Photo-Optical Instrumentation Engineers.

Copying of material in this book for internal or personal use, or for the internal or personal use of specific clients, beyond the fair use provisions granted by the U.S. Copyright Law is authorized by SPIE subject to payment of copying fees. The Transactional Reporting Service base fee for this volume is $\$ 18.00$ per article (or portion thereof), which should be paid directly to the Copyright Clearance Center (CCC), 222 Rosewood Drive, Danvers, MA 01923. Payment may also be made electronically through CCC Online at copyright.com. Other copying for republication, resale, advertising or promotion, or any form of systematic or multiple reproduction of any material in this book is prohibited except with permission in writing from the publisher. The CCC fee code is 0277-786X/15/\$18.00.

Printed in the United States of America.

Publication of record for individual papers is online in the SPIE Digital Library.

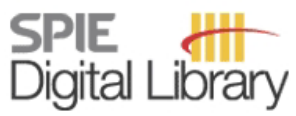

SPIEDigitalLibrary.org

Paper Numbering: Proceedings of SPIE follow an e-First publication model, with papers published first online and then in print. Papers are published as they are submitted and meet publication criteria. A unique citation identifier (CID) number is assigned to each article at the time of the first publication. Utilization of CIDs allows articles to be fully citable as soon as they are published online, and connects the same identifier to all online, print, and electronic versions of the publication. SPIE uses a six-digit CID article numbering system in which:

- The first four digits correspond to the SPIE volume number.

- The last two digits indicate publication order within the volume using a Base 36 numbering

system employing both numerals and letters. These two-number sets start with 00, 01, 02, 03, 04,

05, 06, 07, 08, 09, 0A, OB ... 0Z, followed by 10-1Z, 20-2Z, etc.

The CID Number appears on each page of the manuscript. The complete citation is used on the first page, and an abbreviated version on subsequent pages. 


\title{
Contents
}

\author{
ix Authors \\ xiii Conference Committee \\ xvii Introduction
}

SESSION 1 KEYNOTE SESSION

942304 Graphoepitaxial and chemoepitaxial methods for creating line-space patterns at 33nm pitch: comparison to a HVM process (Keynote Paper) [9423-3]

\section{SESSION 2 DSA PROCESS AND INTEGRATION}

942305 Implementation of templated DSA for via layer patterning at the 7nm node (Invited Paper) [9423-4]

942306 Directed self-assembly (DSA) grapho-epitaxy template generation with immersion lithography [9423-5]

942307 Customization and design of directed self-assembly using hybrid prepatterns [9423-6]

942309 Understanding of PS-b-PMMA phase segregation under laser-induced millisecond thermal annealing [9423-8]

\section{SESSION 3 UV-NIL FOR IC MANUFACTURING}

9423 OC Nanoimprint system development and status for high volume semiconductor manufacturing [9423-11]

9423 OD HVM readiness of nanoimprint lithography templates: defects, CD, and overlay [9423-12]

$9423 \mathrm{OE} \quad$ Advanced electric-field scanning probe lithography on molecular resist using active cantilever (Invited Paper) [9423-13]

9423 OF Optimization of near-field scanning optical lithography [9423-14] 
9423 Ol Pattern transfer into silicon using sub-10 nm masks made by electron beam induced deposition [9423-17]

9423 OK Fabrication of functional electromechanical nanowire resonators by focused ion-beam (FIB) implantation [9423-19]

SESSION 6 METROLOGY AND INSPECTION FOR DIRECTED SELF-ASSEMBLY: JOINT SESSION WITH CONFERENCES 9423 AND 9424

9423 OM Defect mitigation and root cause studies in IMEC's $14 \mathrm{~nm}$ half-pitch chemo-epitaxy DSA flow [9423-21]

SESSION 7 DSA MATERIALS AND PROCESSES I: JOINT SESSION WITH CONFERENCES 9425 AND 9423

9423 ON Impact of materials selection on graphoepitaxial directed self-assembly for line-space patterning [9423-22]

942300 Imprint directed self-assembly of cylinder-forming Si-containing block copolymer for $6 \mathrm{~nm}$ half-pitch line patterning [9423-23]

SESSION 8 DSA MATERIALS AND PROCESSES II: JOINT SESSION WITH CONFERENCES 9425 AND 9423

9423 OR Toward high-performance quality meeting IC device manufacturing requirements with AZ SMART DSA process [9423-26]

9423 OS Fin formation using graphoepitaxy DSA for FinFET device fabrication [9423-27]

\section{SESSION 9 NANOIMPRINT LITHOGRAPHY: NON-IC APPLICATIONS}

9423 OT Smart plastic functionalization by nanoimprint and injection molding (Invited Paper) [9423-28]

9423 OU Development of NIL processes for PV applications [9423-29]

9423 OW Shape change of cured 2D and 3D nanostructures from imprint lithography [9423-88]

\section{SESSION 10 MULTIBEAM LITHOGRAPHY}

942310 Thermal effect induced wafer deformation in high-energy e-beam lithography [9423-35]

942311 Comparison between e-beam direct write and immersion lithography for 20nm node [9423-36]

iv 
$942312 \quad$ Alternative stitching method for massively parallel e-beam lithography [9423-37]

942313 Development of ballistic hot electron emitter and its applications to parallel processing: active-matrix massive direct-write lithography in vacuum and thin films deposition in solutions [9423-38]

SESSION 11 DSA LINE AND VIA PATTERNING

942314 Self-aligned line-space pattern customization with directed self-assembly graphoepitaxy at $24 \mathrm{~nm}$ pitch (Invited Paper) [9423-39]

942315 Impact of BCP asymmetry on DSA patterning performance [9423-40]

942316 Directed self-assembly lithography using coordinated line epitaxy (COOL) process [9423-41]

942317 Template affinity role in CH shrink by DSA planarization [9423-42]

942318 Cross-sectional imaging of directed self-assembly block copolymers [9423-43]

SESSION 12 ELECTRON-BEAM APPLICATIONS

942319 Massively parallel e-beam inspection: enabling next-generation patterned defect inspection for wafer and mask manufacturing (Invited Paper) [9423-44]

94231 A Fabrication of NIL templates and diffractive optical elements using the new Vistec SB4050 VSB e-beam writer [9423-45]

9423 IB Verification of e-beam direct write integration into 28nm BEOL SRAM technology [9423-46]

9423 1C Ready for multi-beam exposure at $5 \mathrm{kV}$ on MAPPER tool: lithographic and process integration performances of advanced resists/stack [9423-47]

9423 ID Contour-based kernel modeling and verification for e-beam lithography [9423-48]

SESSION 13 DSA DESIGN FOR MANUFACTURABILITY: JOINT SESSION WITH CONFERENCES 9423, 9426, AND 9427

9423 IE Verification of directed self-assembly (DSA) guide patterns through machine learning [9423-49]

9423 IF Experimental study of sub-DSA resolution assist features (SDRAF) [9423-50]

9423 IG DSA-aware assist features [9423-51] 
$942311 \quad$ Advantages and limitations of density functional theory in block copolymer directed selfassembly [9423-53]

$94231 \mathrm{~J}$ Effect of chemoepitaxial guiding underlayer design on the pattern quality and shape of aligned lamellae for fabrication of line-space patterns [9423-54]

$94231 \mathrm{~K}$ The effects of geometry and chemistry of nanopatterned substrates on the directed selfassembly of block-copolymer melts [9423-55]

$94231 \mathrm{~L} \quad$ Effect of $\mathrm{XN}$ and underlayer composition on self-assembly of thin films of block copolymers with energy asymmetric block [9423-56]

POSTER SESSION: NANOIMPRINT LITHOGRAPHY

$94231 \mathrm{M} \quad$ Negative e-beam resists using for nano-imprint lithography and silicone mold fabrication [9423-57]

9423 iN Advanced nano lithography via soft materials-derived and reversible nano-patterning methodology for molding of infrared nano lenses [9423-58]

\section{POSTER SESSION: ELECTRON-BEAM LITHOGRAPHY AND APPLICATIONS}

9423 IP An instruction-based high-throughput lossless decompression algorithm for e-beam directwrite system [9423-60]

$94231 Q \quad$ "Fast" and "thick" e-beam resists exposed with multi-beam tool at 5 keV for implants and mature nodes: experimental and simulated model study [9423-61]

\section{POSTER SESSION: NOVEL LITHOGRAPHY AND APPLICATIONS}

$94231 \mathrm{U} \quad$ Electric-field assisted assembly of core-shell nanoparticle arrays for contact hole patterning [9423-67]

9423 IV Photo-induced large-scale circular surface-relief diffraction gratings on azo-glass [9423-68]

$94231 \mathrm{~W}$ Solid immersion optical lithography: tuning the prism/sample interface for improved ultra high-NA, high aspect ratio resist patterns over large exposure fields [9423-69]

POSTER SESSION: DIRECTED SELF-ASSEMBLY

9423 1X Computational analysis of hole placement errors for directed self-assembly [9423-71]

9423 IY Coarse-grained molecular dynamics modeling of the kinetics of lamellar BCP defect annealing [9423-72] 
942312 Directed self-assembly of diblock copolymers in cylindrical confinement: effect of underfilling and air-polymer interactions on configurations [9423-73]

942320 Tilting of lamellar domains on neutral random copolymer brushes [9423-74]

942322 Mapping self-assembled dots and line arrays by image analysis for quantification of defect density and alignment [9423-77]

942324 193i lithography for contact doubling with grapho-epitaxy DSA: a simulation study [9423-79]

942325 Nanomechanical properties of solvent cast PS and PMMA polymer blends and block copolymers [9423-80]

942326 Creation of guiding patterns for directed self-assembly of block copolymers by resistless direct e-beam exposure [9423-81]

9423 2A Study of DSA interaction range using Gaussian convolution [9423-85]

$94232 \mathrm{C} \quad$ Barriers to defect melting in chemo-epitaxial directed self-assembly of lamellar-forming diblock copolymer/homopolymer blends [9423-87] 
Proc. of SPIE Vol. $9423942301-8$

Downloaded From: https://www.spiedigitallibrary.org/conference-proceedings-of-spie on 25 Apr 2023 Terms of Use: https://www.spiedigitallibrary.org/terms-of-use 


\title{
Authors
}

Numbers in the index correspond to the last two digits of the six-digit citation identifier (CID) article numbering system used in Proceedings of SPIE. The first four digits reflect the volume number. Base 36 numbering is employed for the last two digits and indicates the order of articles within the volume. Numbers start with 00, 01, 02, 03, 04, 05, 06, 07, 08, 09, 0A, 0B...0Z, followed by 10-1Z, 20-2Z, etc.

\author{
Ahmad, Ahmad, OE \\ Ahn, Chi Won, iN \\ Amann, A., 22 \\ Andén, Thomas, ОT \\ Angelov, Tihomir, $\mathrm{OE}$ \\ Arellano, Noel, 07 \\ Argoud, M., 17 \\ Atanasov, Ivaylo, $\mathrm{OE}$ \\ Aydogan, Cemal, $\mathrm{OE}$ \\ Azuma, Tsukasa, 16 \\ Balakrishnan, Srinivasan, 07 \\ Barke, S., OU \\ Barnola, S., 17 \\ Bayana, Hareen, OM \\ Bayle, Sébastien, 12 \\ Bekaert, Joost, 05, 06, 18, 1F, 2A \\ Bérard-Bergery, S., 17, 24 \\ Bilenberg, Brian, OT \\ Blaikie, Richard J., IW \\ Bläsi, B., OU \\ Bonnecaze, Roger T., OW \\ Borrisé, Xavier, OK, 26 \\ Bos, S., 17 \\ Bouanani, S., 17 \\ Brandt, Pieter, 11, 12, 1C \\ Brink, Markus, 07, 14 \\ Bucchignano, James, 14 \\ Bunday, Benjamin D., 19 \\ Burns, Sean, OS \\ Butschke, Joerg, $1 \mathrm{~A}$ \\ Cai, Sibo, 1E \\ Cao, Yi, 05, OM, OR, 15 \\ Carilli, Michael, 2C \\ Carpenter, Corinne L., 1 Z \\ Chamiot-Maitral, G., 17 \\ Chan, Boon Teik, 05, OM \\ Chang, Shih-wei, ON \\ Chen, Cheng-Hung, 1D \\ Chen, M. C., 1M \\ Chen, P. S., 10 \\ Cheng, Joy, 07, 14 \\ Chevalier, X., 17 \\ Chien, Tsung-Chih, ID \\ Chikashi, Ito, OM \\ Cho, Wooyong, OS \\ Choi, Byungil, $1 \mathrm{E}$ \\ Choi, Kang-Hoon, 1B \\ Chopra, Meghali J., OW \\ Colburn, Matthew, OS, 14
}

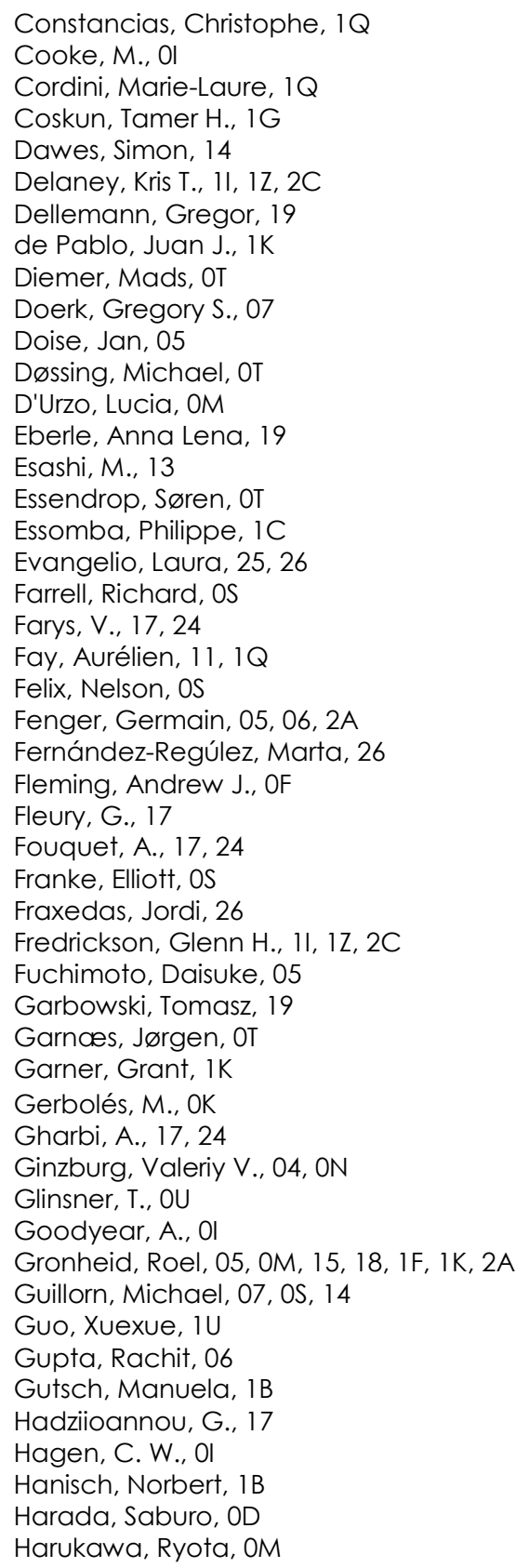


Hauser, H., OU

Hayashi, Naoya, OD

Hazart, J., 17, 24

He, Yuan, 06

Henderson, Clifford L., 1 J, 1L, 1Y

Her, YoungJun, OR

Hetzer, David, OS

Hofer, Manuel, OE

Hohle, Christoph, 1B

Holdsworth, John L., OF

Holz, Mathias, OE

Hong, C. S., $1 M$

Hong, Le, 06

Hsu, Yautzong, 00

Hur, Su-Mi, $1 \mathrm{~K}$

Hustad, Phillip D., 04, ON

Ibbotson, Dale, 11

Ichimura, Koji, OD

Ikegami, N., 13

Irmscher, Mathias, 1A

Ishchuk, Valentyn, OE

Ivanov, Tzvetan, $\mathrm{OE}$

Izumi, Kenichi, 2C

Jacobs, Alan G., 09

Jang, Hyun Ik, $1 \mathrm{~N}$

Jeon, Seok Woo, iN

Johansson, Alicia C., OT

Joseph, Eric, 14

Jung, Sung Gon, OS

Jussot, Julien, $1 \mathrm{C}$

Kaestner, Marcus, OE

Kamerbeek, M. J., Ol

Kanai, Hideki, 16

Karageorgos, loannis, 05

Kasahara, Yusuke, 16

Kawamonzen, Yoshiaki, 16

Kemen, Thomas, 19

Khunsin, W., 22

Kihara, Naoko, 16

Kim, Bongkeun, 2C

Kim, Hee Yeoun, $1 \mathrm{~N}$

Kim, JiHoon, OM, OR, 15

Kim, Woo Choong, 1N

Kitano, T., 1X

Klaus, David, 14

Ko, Akiteru, OS

Kobayashi, Katsutoshi, 16

Kodera, Katsuyoshi, 16

Koepernik, Corinna, 1A

Kojima, A., 13

Koshida, N., 13

Kristensen, Anders, OT

Kristiansen, Tommy Tungelund, OT

Krivoshapkina, Yana, OE

Kubota, Hitoshi, 16

Kuo, David, 00

Kurihara, Masaaki, OD

Laachi, Nabil, 1I, 1Z, 2C

Lafferty, Neal, 06

Lai, Kafai, OS
Lapeyre, C., 17

Lattard, Ludovic, 1C, 1Q

Latypov, Azat, $1 \mathrm{G}$

Lawson, Richard A., 1J, 1L, 1Y

Lee, Kim Y., 00

Lei, Junjiang, 06

Leibold, James, $1 \mathrm{~V}$

Lenk, Steve, OE

Li, Mingqi, ON

Lie, Fee Li, OS

Liedel, Clemens, 09

Light, Scott L., 04, ON

Lin, Burn J., 1D

Lin, Guanyang, 05, 0M, OR, 15

Lin, Lan, 10

Lin, Shy-Jay, 10, 1D, 1P

Lipowicz, Hubert-Seweryn, OE

Lippincott, George, 06

Liu, Chi-Chun (Charlie), 07, os

Liu, Jimmy, 11

Llobet, J., OK

Lorenzoni, Matteo, 25, 26

Lowrey, Sam, IW

Ludovice, Peter J., 1J, 1L, 1Y

Lugani, Gurpreet S., 04, ON

Ma, Yuansheng, 06

Madsen, Morten Hannibal, OT

Mahadevapuram, Nikhila, 20

Malloy, Matt, 19

Martens, Stephan, 1A

Matsuzaki, K., $1 \mathrm{X}$

Mayer, Theresa S., $1 \mathrm{U}$

Mebiene, Armel-Petit, 1C

Mikkelsen, Niels Jørgen, OT

Milléquant, Matthieu, 12

Millward, Dan B., 04, ON

Minegishi, Shinya, 16

Minzari, Daniel, OT

Mitra, Indranil, 20

Miyagi, Ken, 16

Miyaguchi, H., 13

Miyazoe, Hiroyuki, 14

Mohanty, Nihar, OS

Monget, C., 17

Morris, M. A., 22

Mukhtar, Maseeh, 19

Müller, C., OU

Muramatsu, M., $1 \mathrm{X}$

Muroyama, M., 13

Nafus, Kathleen, OM, 1F, 2A

Nagai, Takaharu, OD

Nagaswami, Venkat, OM

Nakano, T., IX

Nation, Benjamin D., 1J, 1L, 1 Y

Navarro, Christophe, 17, 25

Nealey, Paul F., OM, 15, $1 \mathrm{~K}$

Nicolet, Célia, 17, 25

Nielsen, Theodor, OT

Niroomand, Ardavan, 04

Nishino, H., 13 
Nomura, Satoshi, 16

Ober, Christopher K., 09

Okabe, Kye, 18

Ozlem, Melih, OS

Pain, Laurent, $1 Q$

Park, Jae Hong, iN

Park, Jun Yong, $1 \mathrm{~N}$

Parnell, Doni, OM

Pathangi, Hari, OM

Pérez-Murano, Francesc, OK, 25, 26

Perraud, L., 17, 24

Petermann, Claire, OR

Peters, Andrew J., 1 J, 1L, 1Y

Peters, Jan Hendrik, 19

Pimenta-Barros, Patricia, 17, 1C, 24

Pourteau, Marie-Line, 1C

Pradelles, Jonathan, $1 \mathrm{C}$

Quach, Dung, 04, 0N

Quoi, Kathy, 19

Rangelow, Ivo W., OE

Rastogi, Vinayak, OS

Renault, Guillaume, 12

Rettner, Charles T., 07

Reum, Alexander, $\mathrm{OE}$

Rincon-Delgadillo, Paulina, OM, IK

Routley, Ben S., OF

Ryckaert, Julien, 05

Sabat, Ribal Georges, IV

Sailer, Holger, 1 A

San Paulo, Alvaro, 25

Sanders, Daniel P., 07, 14

Sansa, M., OK

Sardana, Charu, 11

Sato, Hironobu, 16

Schnabel, Bernd, 1 A

Schneider, P., OU

Scotuzzi, M., Ol

Seidel, Robert, 1B

Seidel, Robert, $1 \mathrm{~K}$

Seino, Yuriko, 16

Servin, Isabelle, 1C, 1Q

Shan, Jianhui, OR

Sheu, Gene, $1 \mathrm{M}$

Shim, Seongbo, $1 \mathrm{E}$

Shin, Jaw-Jung, 1D

Shin, Youngsoo, $1 \mathrm{E}$

Shiraishi, Masayuki, 16

Shirakashi, J., 13

Shy, S. L., $1 \mathrm{M}$

Simão, C., 22

Singh, Gurpreet, 07

Smistrup, Kristian, OT

Somervell, Mark, 05, OS

Sotomayor Torres, C. M., 22

Sreenivasan, S. V., OC

Steidel, Katja, 1B

Stein, Gila E., 20

Strane, Jay, OS

Strzalka, Joseph, 20

Suda, R., 13
Sugata, M., 13

T. V., Anil Kumar, $1 \mathrm{M}$

Taboryski, Rafael, OT

Takeishi, Hiroaki, OC

Tang, Peter Torben, OT

Thamdrup, Lasse H., OT

Thiam, Ndeye Arame, 1C, 1Q

Thiel, Brad, 19

Thompson, Michael O., 09

Thrun, Xaver, 1B

Tiberio, Richard, 18

Tiron, R., 17, 24

Tjio, Melia, 07

Tobana, Toshikatsu, 16

Tokai, K., OU

Tomita, T., 1X

Torres, J. Andres, 06

Totsu, K., 13

Tranquillin, Céline, 12

Trefonas, Peter, III, 04, 0N

Tritchkov, Alexander, 06

Truong, Hoa, 07

Tsai, HsinYu, 07, OS, 14

Tsutsumi, Tomohiko, OR

Tuchapsky, D., 22

Tucher, N., OU

Tung, Maryann C., 18

Vandenberghe, Geert, 05, 06, IF

Vandenbroeck, Nadia, OM

Van Den Heuvel, Dieter, OM

Van Look, Lieve, OM

Volk, A., OU

Wang, W. C., 10

Wang, Wen-Chuan, IP

Wellens, Ch., OU

Werner, Thomas, 1B

Wieland, Marco, 11, 12, 1C

Williamson, Lance, 15, $1 \mathrm{~K}$

Wong, H.-S. Philip, 18, 1F, 2A

Word, James, 06

Wu, Cheng-Chi, IP

Wu, Hengpeng, OR

Wu, Janet, ON

Wurm, Stefan, 19

Xiao, Shuaigang, 00

Yagi, M., 13

Yamamoto, K., IX

Yang, Jaewon, IE

Yang, Jensen, $1 \mathrm{P}$

Yang, Seunghune, $1 \mathrm{E}$

Yang, Shao-Ming, $1 \mathrm{M}$

Yang, XiaoMin, 00

Yi, He, 18, 1F, 2A

Yin, Jian, $O R$

Yoshida, Kouji, OD

Yoshida, S., 13

Yoshida, T., 13

You, Jan-Wen, 1D

Zalkovskij, Maksim, OT

Zeidler, Dirk, 19 
Proc. of SPIE Vol. $9423942301-12$

Downloaded From: https://www.spiedigitallibrary.org/conference-proceedings-of-spie on 25 Apr 2023 Terms of Use: https://www.spiedigitallibrary.org/terms-of-use 


\section{Conference Committee}

Symposium Chair

Mircea V. Dusa, ASML US, Inc. (United States)

Symposium Co-chair

Bruce W. Smith, Rochester Institute of Technology (United States)

Conference Chair

Douglas J. Resnick, Canon Nanotechnologies, Inc. (United States)

Conference Co-chair

Christopher Bencher, Applied Materials, Inc. (United States)

Conference Program Committee

Frank E. Abboud, Intel Corporation (United States)

Alan D. Brodie, KLA-Tencor Corporation (United States)

Kenneth R. Carter, University of Massachusetts Amherst (United States)

Juan J. de Pablo, The University of Chicago (United States)

Elizabeth A. Dobisz, HGST (United States)

Michael A. Guillorn, IBM Thomas J. Watson Research Center

(United States)

Naoya Hayashi, Dai Nippon Printing Company Ltd. (Japan)

Daniel J. C. Herr, The University of North Carolina at Greensboro

(United States)

Tatsuhiko Higashiki, Toshiba Corporation (Japan)

James A. Liddle, National Institute of Standards and Technology

(United States)

Shy-Jay Lin, Taiwan Semiconductor Manufacturing Company Ltd.

(Taiwan)

Hans Loeschner, IMS Nanofabrication AG (Austria)

John G. Maltabes, Hewlett-Packard Laboratories (United States)

Dan B. Millward, Micron Technology, Inc. (United States)

Laurent Pain, CEA-LETI (France)

Ivo W. Rangelow, Technische Universität Ilmenau (Germany)

Benjamen M. Rathsack, Tokyo Electron America, Inc. (United States)

Ricardo Ruiz, HGST (United States)

Frank M. Schellenberg, Consultant (United States)

Helmut Schift, Paul Scherrer Institut (Switzerland)

Ines A. Stolberg, Vistec Electron Beam Lithography Group (Germany) 
Kevin T. Turner, University of Pennsylvania (United States)

Marco J. Wieland, MAPPER Lithography (Netherlands)

Wei Wu, The University of Southern California (United States)

Todd R. Younkin, Intel Corporation (United States)

\section{Session Chairs}

1 Keynote Session

Douglas J. Resnick, Canon Nanotechnologies, Inc. (United States)

Christopher Bencher, Applied Materials, Inc. (United States)

2 DSA Process and Integration

Joy Y. Cheng, IBM Research - Almaden (United States)

Dan B. Millward, Micron Technology, Inc. (United States)

3 UV-NIL for IC Manufacturing

Naoya Hayashi, Dai Nippon Printing Company Ltd. (Japan)

Tatsuhiko Higashiki, Toshiba Corporation (Japan)

4 Scanning Probe Lithography

Ivo W. Rangelow, Technische Universität Ilmenau (Germany)

Alan D. Brodie, KLA-Tencor Corporation (United States)

5 Novel Lithography and Applications

Wei Wu, The University of Southern California (United States)

Laurent Pain, CEA-LETI (France)

6 Metrology and Inspection for Directed Self-Assembly: Joint Session with Conferences 9423 and 9424

Martha I. Sanchez, IBM Research - Almaden (United States)

Daniel J. C. Herr, The University of North Carolina at Greensboro (United States)

7 DSA Materials and Processes I: Joint Session with Conferences 9425 and 9423

Juan J. de Pablo, The University of Chicago (United States)

Roel Gronheid, IMEC (Belgium)

8 DSA Materials and Processes II: Joint Session with Conferences 9425 and 9423

Todd R. Younkin, Intel Corporation (United States)

Sean D. Burns, IBM Corporation (United States)

9 Nanoimprint Lithography: Non-IC Applications

Helmut Schift, Paul Scherrer Institut (Switzerland)

Kenneth R. Carter, University of Massachusetts Amherst (United States) 
10 Multibeam Lithography

Hans Loeschner, IMS Nanofabrication AG (Austria)

Frank E. Abboud, Intel Corporation (United States)

11 DSA Line and via Patterning

Ricardo Ruiz, HGST (United States)

Benjamen M. Rathsack, Tokyo Electron America, Inc. (United States)

12 Electron-Beam Applications

Shy-Jay Lin, Taiwan Semiconductor Manufacturing Company Ltd. (Taiwan)

Ines A. Stolberg, Vistec Electron Beam GmbH (Germany)

13 DSA Design for Manufacturability: Joint Session with Conferences

9423, 9426, and 9427

Michael A. Guillorn, IBM Thomas J. Watson Research Center (United States)

Sachiko Kobayashi, Toshiba Corporation (Japan)

Vivek K. Singh, Intel Corporation (United States)

14 DSA Modeling

Frank M. Schellenberg, Consultant (United States)

Elizabeth A. Dobisz, HGST (United States) 
Proc. of SPIE Vol. $9423942301-16$

Downloaded From: https://www.spiedigitallibrary.org/conference-proceedings-of-spie on 25 Apr 2023 Terms of Use: https://www.spiedigitallibrary.org/terms-of-use 


\section{Introduction}

The semiconductor industry has relentlessly marched down a path which has enabled device dimensions with half pitches as small as $15 \mathrm{~nm}$ to be realized. Spacer multiple patterning in particular has been invaluable for the NAND Flash market and, in recent years, has found its way into both DRAM and logic based devices. Spacer patterning has not only introduced additional processing costs, but also enabled scaling greater than the tradition 0.7 factor, with multiple device makers continuing to report lower cost per function.

Several options exist to extend the semiconductor technology roadmap beyond the $14 \mathrm{~nm}$ node. Both top down and bottom up lithographic technologies are now part of the ITRS roadmap, and among the candidates are maskless lithography, nanoimprint lithography and directed self-assembly (DSA). In addition to enabling cost effective solutions for the logic and memory markets, these lithographic solutions also hold the promise of enabling many other key markets that also require high resolution lithography. Included in this list are patterned media for hard disk drives, high brightness light emitting diodes and several display related applications.

Any lithographic technology needs to address several key requirements beyond just resolution. Critical parameters include layout restrictions, defectivity, overlay, grid correction, throughput and cost. In addition, any consideration for high volume manufacturing must include a supporting infrastructure which allows a seamless integration of the new technology into a production facility. The goal of the Alternative Lithography Conference was to review new lithographic solutions, as well as monitor the progress of technologies that could one day become mainstream. The conference did not limit itself to the options listed in the ITRS roadmap and also considered innovative approaches including: plasmonics, micromirror optical lithography, interferometric lithography, tip-based nanolithography, scanning array lithography, dip pen printing and drop-ondemand inkjet lithography.

This year's conference consisted of more than 78 invited and contributed presentations on these topics. The conference was held over three and a half days, with fourteen oral sessions, a poster session and a panel discussion.

The Alternative Lithography Conference was highlighted by three Keynote presentations Monday afternoon. Speakers included: Dr. Yan Borodovsky from Intel, Dr. Toshiaki Ikoma from Canon, and Dr. Dan Millward of Micron. Dr. Borodovsky emphasized the need for edge placement on complimentary patterning layers and suggested that work was needed on selective growth mechanisms to meet pattern placement specifications. Dr. Ikoma introduced Canon's nanoimprint lithography program and discussed both progress in the technology space, as well as introducing new imprint systems to the community. Dr. Millward gave an insightful overview on DSA and discussed both progress 
made, technical hurdles and benchmarked performance versus SAQP (spacer quadruple patterning).

DSA still commands the most attention at this conference and speakers from Intel, TEL and elsewhere reported significant improvements on defect density, for both hole and dense line patterns.

Step and repeat nanoimprint lithography was covered by speakers from Toshiba, Canon, Canon Nanotechnologies and Dai Nippon Imprinting. The invited talk from Toshiba reviewed both the progress made, as well as infrastructure areas where help was still required.

Beam lithography talks were highlighted by two presentations: One from IMS Nanofabrication, which reviewed their progress on a multi-beam mask writer; and a second from Sematech and Zeiss, which discussed the progress made on a multibeam inspection tool for both wafers and masks.

A conference of this magnitude cannot be successful without a dedicated program committee, and our thanks go out to all the committee members for their tireless review of abstracts and help with the organization of the individual sessions. Special thanks are also due to Alex Liddle and Martha Sanchez for hosting a panel discussion on the topic: Dimensional Scaling, Design Optimization, and Metrology: What are We Missing?

Next year, Chris Bencher from Applied Materials and Joy Cheng from IBM will chair the conference. We look forward to your continued support through the submission of abstracts and manuscripts, and look forward to seeing everyone next year.

Douglas J. Resnick Christopher Bencher 